\title{
On Murine Mammary Epithelial Stem Cells: Discovery, Function, and Current Status
}

\author{
Jeffrey M. Rosen \\ Department of Molecular and Cellular Biology and Department of Medicine, Baylor College of Medicine, \\ Houston, Texas 77030-3498 \\ Correspondence: jrosen@bcm.edu
}

$\mathrm{R}_{\mathrm{r}}^{\mathrm{e}}$ emarkable progress has been made in the past decade in the isolation and characterization of mouse mammary stem cells and progenitors, as nicely reviewed in the article by Visvader and Smith (2011). Following in the footsteps of the hematopoietic system and analogous to bone marrow transplantation, the mammary gland can be reconstituted following transplantation of cells into the cleared mammary fat pad (see review by Medina 2011). Taking advantage of these similarities as well as the availability of genetically engineered mice (GEM), our laboratory initially used magnetic bead and fluorescence-activated cell sorting (FACS) and SCA enhanced green fluorescent protein (EGFP) knock-in mice to identify mammary gland progenitors (Welm et al. 2002). We also attempted to identify and isolate quiescent cells using a BrdU label retention strategy that had been successfully applied in the epidermal and intestinal epithelium. Subsequently, the identification of several cell-surface markers expressed on mammary stem cells and progenitors has resulted in an explosion in the field, and helped to define a preliminary mammary cell lineage hierarchy. These studies on the normal mammary gland have also provided the basis for hypotheses into potential mechanisms accounting for the heterogeneity of breast cancer subtypes (Behbod and Rosen 2004).

One intrinsic difference between the hematopoietic system and the mammary gland, how- ever, is the requirement for tissue dissociation in the latter case to facilitate the isolation of single cells required for FACS sorting. Even when using freshly isolated cells, there is a concern that these rather lengthy dissociation protocols may alter the expression of cell-surface molecules and properties of cells following disruption of the mammary gland architecture. Even shortterm cell culture of primary mammary epithelial cells may alter the expression of cell-surface molecules. At present, single gene markers of mammary stem cells have not been identified, so the application of knock-in mice, e.g., the use of LGR5-EGFP to identify intestinal stem cells and perform lineage-tracing experiments (Barker et al. 2007), has not been feasible. One alternative approach may be to use pathway reporters, as recently described by Zeng and Nusse (2010), who used an axin-lacZ knock-in mouse to identify cells with canonical Wnt signaling with increased mammary repopulating activity. We have used a similar approach in a p53-null mouse mammary cancer model following lentiviral transduction with a Wnt reporter construct to identify cells with enhanced canonical Wnt signaling. These cells displayed a significant overlap with cell-surface markers in the basal-like tumors shown to enrich for tumorinitiating cells (Zhang et al. 2010).

The use of multiple pathway reporters with different fluorescent reporters may provide a

Editors: Mina J. Bissell, Kornelia Polyak, and Jeffrey M. Rosen

Additional Perspectives on The Mammary Gland as an Experimental Model available at www.cshperspectives.org

Copyright (C) 2012 Cold Spring Harbor Laboratory Press; all rights reserved; doi: 10.1101/cshperspect.a013268

Cite this article as Cold Spring Harb Perspect Biol 2012;4:a013268 
J.M. Rosen

new approach to complement the current dependence on cell-surface markers. Fluorescent reporters also have the potential to help precisely visualize and model the location of mammary stem cells and progenitors in situ using multiphoton and other sophisticated microscopic techniques. The ability to visualize single stem cells in their niche environment and to follow both symmetric versus asymmetric division ultimately will be required for the next advances in the field. Recent studies on the paracrine effects of the steroid hormones, estrogen and progesterone, on mammary gland stem cells and progenitors illustrate the need to understand the spatial relationships among the various epithelial and stromal cell types present in the mammary gland. These studies will need to include cells from the immune system such as macrophages, neutrophils, etc., and derivatives of mesenchymal stem cells. Hopefully, in the near future it may be feasible to reconstitute and study these interactions in vitro, but for the present time this can be studied in GEM models. In addition, there is increasing evidence for the coexistence of quiescent and active adult stem cells in mammals (Li and Clevers 2010), but these distinct populations and their spatial and temporal relationships in the mammary gland remain to be discovered. Application of single-cell analysis using newly developed microfluidic platforms has the potential to help elucidate the potential heterogeneity of signaling pathways and gene expression in mammary stem cells and progenitors. Finally, there is a critical need for lineage-tracing experiments in the normal mammary gland to validate the proposed hierarchy for stem cells and progenitors, as well as to identify the cells of origin for different subtypes of breast cancer. Comparative studies of the murine and human stem cell populations in both the normal mammary gland and different breast cancer subtypes hold enormous potential for the future. Thus, despite the remarkable progress in this field, much remains to be done.

\section{REFERENCES}

${ }^{*}$ Reference is also in this collection.

Barker N, van Es JH, Kuipers J, Kujala P, van den Born M, Cozijnsen M, Haegebarth A, Korving J, Begthel H, Peters PJ, et al. 2007. Identification of stem cells in small intestine and colon by marker gene Lgr5. Nature 449: $1003-$ 1007.

Behbod F, Rosen JM. 2004. Will cancer stem cells provide new therapeutic targets? Carcinogenesis 4: 703-711.

Li L, Clevers H. 2010. Coexistence of quiescent and active adult stem cells in mammals. Science 327: 542-545

* Medina D. 2011. Of mice and women: A short history of mouse mammary cancer research with an emphasis on the paradigms inspired by the transplantation method. Cold Spring Harb Perspect Biol doi: 10.1101/cshperspect. a004523.

* Visvader JE, Smith GH. 2011. Murine mammary epithelial stem cells: Discovery, function, and current status. Cold Spring Harb Perspect Biol doi: 10.1101/cshperspect. a004879.

Welm BE, Tepera SB, Venezia T, Graubert TA, Rosen JM, Goodell MA. 2002. Sca-1pos cells in mouse mammary gland represent an enriched progenitor cell population. Dev Biol 245: 42-56.

Zeng YA, Nusse R. 2010. Wnt proteins are self-renewal factors for mammary stem cells and promote their long-term expansion in culture. Cell Stem Cell 6: $568-$ 577.

Zhang M, Atkinson R, Rosen JM. 2010. Selective targeting of radiation-resistant tumor-initiating cells. Proc Natl Acad Sci 107: 3728-3733. 


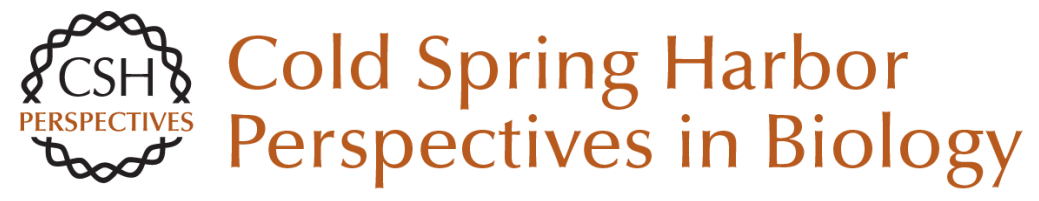

\section{On Murine Mammary Epithelial Stem Cells: Discovery, Function, and Current Status}

Jeffrey M. Rosen

Cold Spring Harb Perspect Biol 2012; doi: 10.1101/cshperspect.a013268

Subject Collection The Mammary Gland as an Experimental Model

On the Role of the Microenvironment in Mammary Gland Development and Cancer

Derek Radisky

On Using Functional Genetics to Understand

Breast Cancer Biology

Kornelia Polyak

On Oncogenes and Tumor Suppressor Genes in the Mammary Gland

Rushika M. Perera and Nabeel Bardeesy

On Leukocytes in Mammary Development and

Cancer

Cyrus M. Ghajar

On Chromatin Remodeling in Mammary Gland

Differentiation and Breast Tumorigenesis Kornelia Polyak

On Hormone Action in the Mammary Gland J.M. Rosen

TGF- $\beta$ Biology in Mammary Development and Breast Cancer

Harold Moses and Mary Helen Barcellos-Hoff
On How Mammary Gland Reprogramming

Metalloproteinases Couple Form with Function Bonnie F. Sloane

On Molecular Mechanisms Guiding Embryonic Mammary Gland Development Gertraud W. Robinson

On Stem Cells in the Human Breast Mark A. LaBarge

On Murine Mammary Epithelial Stem Cells:

Discovery, Function, and Current Status Jeffrey M. Rosen

On In Vivo Imaging in Cancer David Piwnica-Worms

Choosing a Mouse Model: Experimental Biology in Context--The Utility and Limitations of Mouse Models of Breast Cancer Alexander D. Borowsky

Mammary Gland ECM Remodeling, Stiffness, and Mechanosignaling in Normal Development and Tumor Progression

Pepper Schedin and Patricia J. Keely

For additional articles in this collection, see http://cshperspectives.cshlp.org/cgi/collection/

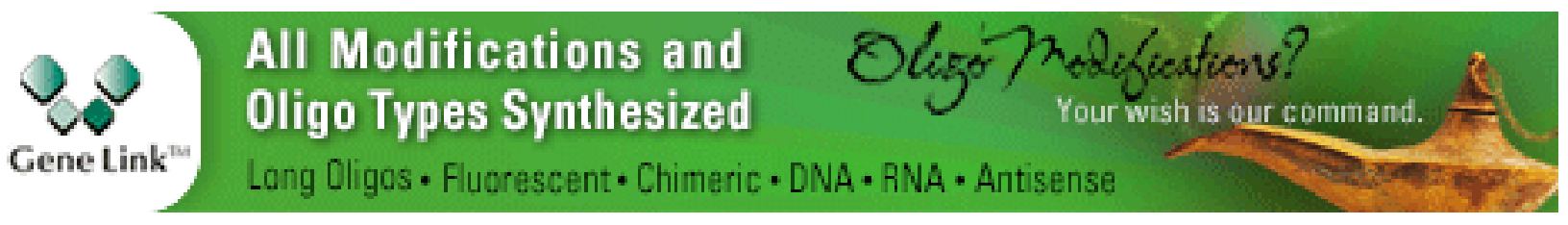


A Compendium of the Mouse Mammary Tumor Biologist: From the Initial Observations in the House Mouse to the Development of Genetically Engineered Mice

Robert D. Cardiff and Nicholas Kenney
Molecular Mechanisms Guiding Embryonic Mammary Gland Development

Pamela Cowin and John Wysolmerski

For additional articles in this collection, see http://cshperspectives.cshlp.org/cgi/collection/

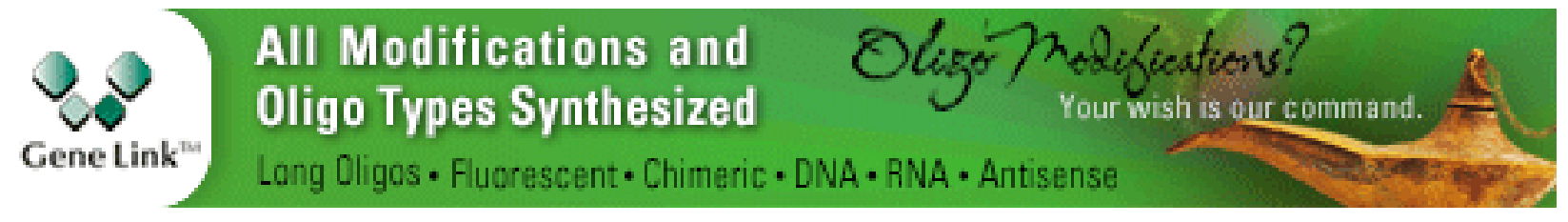

Copyright @ 2012 Cold Spring Harbor Laboratory Press; all rights reserved 